\title{
ENHANCING COLLAPSE-RESISTANCE OF STEEL FRAME JOINTS BASED ON FOLDED AXILLARY PLATES
}

\author{
Bao Meng ${ }^{1,2}$, Liang-De Li ${ }^{1}$, Wei-Hui Zhong ${ }^{1,}{ }^{*}$, Ji-Ping Hao ${ }^{1}$ and Zheng Tan ${ }^{1}$ \\ ${ }^{1}$ School of Civil Engineering, Xi'an University of Architecture \& Technology, Xi'an 710055, China \\ ${ }^{2}$ Key Lab of Structural Engineering and Earthquake Resistance, Ministry of Education (XAUAT), Xi' an 710055, China \\ *(Corresponding author: E-mail: zhongweihui1980@163.com)
}

\section{A B S T RA C T}

To address the limited anti-collapse ability of traditional rigid connections under progressive collapse, this study improves upon the traditional fully welded connection based on folded axillary plates. These folded axillary plates were arranged on the outer side of the beam-end flanges. The movement mechanisms of the tension and compression folded axillary plates under progressive collapse were revealed based on theoretical analysis. Using the validated numerical model, the performance against progressive collapse and key parameters of the improved connection were discussed in detail. No significant effects were observed on the stress of the structure, given the small deformation, and the ultimate deformation and resistance of the steel structure could be significantly improved in later stages. Subsequently, the catenary mechanism in the beam was fully developed, and the beam member was fully utilized. The failure sequence of the substructure with folded axillary plates first involved the folded axillary plate on the tension side gradually straightening, followed by the two plastic regions forming at the beam flange. Afterward, either the tension beam flange at the beam root and the folded axillary plate broke successively or the tension beam flange broke at the point where the plastic hinge moved outward. Additionally, the anti-progressive collapse design process for the folded axillary plate and the design parameters were suggested following theoretical and numerical analyses.

\section{ART I C LE H IS TORY}

\begin{tabular}{|c|c|}
\hline Received: & 9 June 2020 \\
\hline Revised: & 30 November 2020 \\
\hline Accepted: & 2 December 2020 \\
\hline
\end{tabular}

\section{K E Y W O R D S}

\section{Steel frame;}

Folded axillary plate;

Rigid connection;

Collapse-resistance

Numerical analysis;

\section{Introduction}

Progressive collapse of structures caused by accidents can often lead to a painful teaching for structural engineers and is thus widely studied. How to effectively improve the collapse resistance and ensure the overall stability of the structure under accidental load has become a research focus in the field of structural engineering. According to their different understanding of the progressive collapse of structures, Britain [1], Europe [2], the United States [3,4], Japan [5], and other countries, proposed their own unique design codes and standards for the anti-progressive collapse of structures. The structural design methods for preventing progressive collapse mainly include the conceptual design, tie force, local resistance, and alternative load path methods. Among them, the conceptual design method has been sufficiently studied in the national standards and design guidelines, mainly through a reasonable layout of the structure, strengthening the connection, and using ductile materials to enhance the anti-collapse ability of the structure.

At present, considerable progress has been made in research concerning the enhancement of the anti-collapse ability of frame structures based on the conceptual design method. There are generally three methods whereby this enhancement can be achieved. The first method is to enhance the ultimate resistance of the structure, without significantly changing the ultimate deformation of the structure. Yu and Tan [6] used special detailed techniques at little or no additional cost to improve the structural resistance to resist progressive collapse. Wang and Qin [7] made improvements to the diaphragm connection, which could enhance the structural resistance. Meng et al. [8] proposed adding triangular plates at the beam-column connections to increase the combined action between the upper and lower stories, thereby improving the structural resistance. The second method is to improve the ultimate deformation of the structure, without significantly changing the ultimate bearing capacity. Vasdravellis et al. [9] proposed a seismically designed steel selfcentering moment frame against progressive collapse, which could exhibit greater ductility upon incorporation and usage of energy dissipation devices. Wei et al. [10] developed a modified steel frame structure with a corrugated steel plate to increase its ductility. Qiang et al. [11] improved the ductility of reinforced concrete (RC) frame structures by adding kinked rebar configurations. The third method is to simultaneously enhance the ultimate deformation and bearing capacity of the structure. Qiu et al. [12] proposed a retrofit way to enhance the anti-collapse ability of RC frame by installing steel cables between columns. Gao et al. [13] proposed a type of reinforced composite semi-rigid joint that could increase the ultimate deformation and bearing capacity of the structure. Lu et al. [14] proposed a seismic and antiprogressive collapse, composite frame structural system, which had a larger collapse resistance compared to traditional composite frames. Meng et al. [15] proposed a novel RBS connection with "V" shape structural plates, which exhibited good anti-collapse capacity. When the cost of the structure is not significantly increased, simultaneously increasing the ultimate deformation and bearing capacity of the structure against progressive collapse is more economical and efficient to ensure a more robust structure.

According to an experimental study by Lew et al. [16], Li [17], and Meng et al. [18], it has been shown that the collapse resistance of full welded connections and welded unreinforced flange-bolted web connections is poor under the condition of progressive collapse. The brittle fracture of the joint is caused by the crack of the weld and beam-end flange, as shown in Fig. 1. The premature fracture of the beam-end flange restrains the development of the beam axial force and the catenary mechanism of the structure cannot be fully exerted, resulting in the beam not being fully utilized under large deformations. Therefore, to meet the large deformation demand of steel frame structures with traditional rigid connection, it is necessary to improve the traditional rigid joint under the accidental load.

Regarding the limited anti-collapse ability of traditional rigid connections under the condition of progressive collapse, this study improves traditional fullwelded connections by adding folded axillary plates at the beam end. The stress of the structure was not significantly affected for small deformations and the ultimate deformation and corresponding bearing capacity of the frame structure could be considerably improved during later stages. Finally, the catenary mechanism in the beam was fully developed and the beam member was fully utilized. Based on a theoretical analysis, the movement mechanisms of the folded axillary plate were revealed. The anti-collapse performance of the improved connection was analyzed following the verification of the nonlinear numerical model. Additionally, the anti-progressive collapse design process for the folded axillary plate and the design parameters were suggested following theoretical and numerical analyses. 


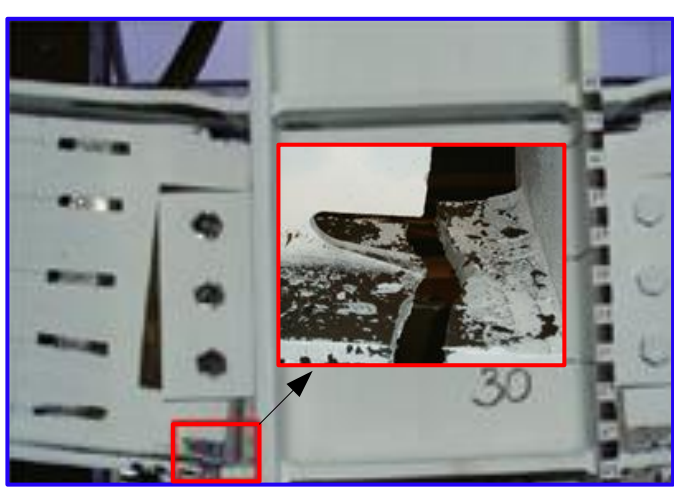

(a)Lew et al.'s test [16]

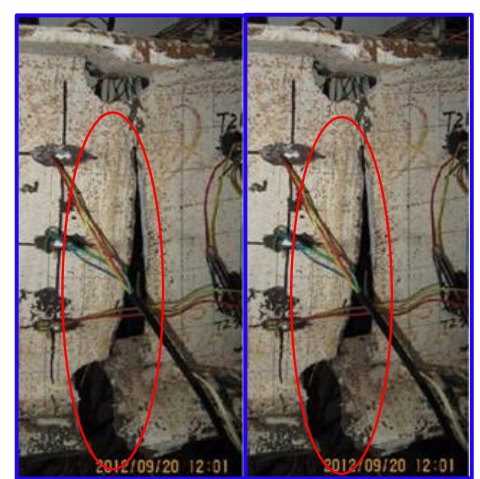

(b) Li 's test [17]

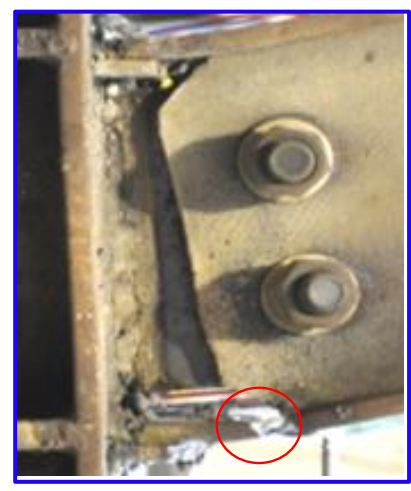

(c) Meng et al.'s test [18]

Fig. 1 Damage mode of traditional rigid joint

\section{Methodology}

\subsection{Improved rigid connection model}

According to the alternate load path method ( ALPM), the double-span beam-column substructure is often adopted to analyze the ability of the substructure against progressive collapse, after the failure of a column because of the relatively simple and clear stress [19-23], as shown in Fig. 2(a). Generally, the resistance development curve of a substructure includes the flexure stage, flexure-catenary mixed stage, and catenary stage. The deformation of the joint will move from elastic to plastic deformation, even for large deformations. The joint mainly bears the combined action of the axial force and bending moment, which develop disproportionately until the joint fails. Under an internal columnremoval scenario, the traditional rigid connection (such as full-welded connections, welded unreinforced flange-bolted web connections, etc.) loses its deformation and bearing capacity early because of the stress concentration at the beam root or the weld (as shown in Fig. 2 (b)), which leads to local failure of the structure. In seismic design, to prevent brittle damage of the full welded connection, the plastic hinge at the beam root is moved outward via the addition of an axillary plate at the beam-column connection, which can increase the ductility of the joint to a certain extent. However, under an internal columnremoval scenario, the rigid connection with axillary plates, subjected to the combined action of the axial force and bending moment, will cause premature cracking at the location where the plastic hinge moves out (as shown in Fig. 2 (c)). The catenary mechanism of the structure is not well developed, which limits the rotational capability of the joint. Hence, it is necessary to improve the anti-collapse ability of this kind of full-welded connection and a full-welded connection with axillary plates.

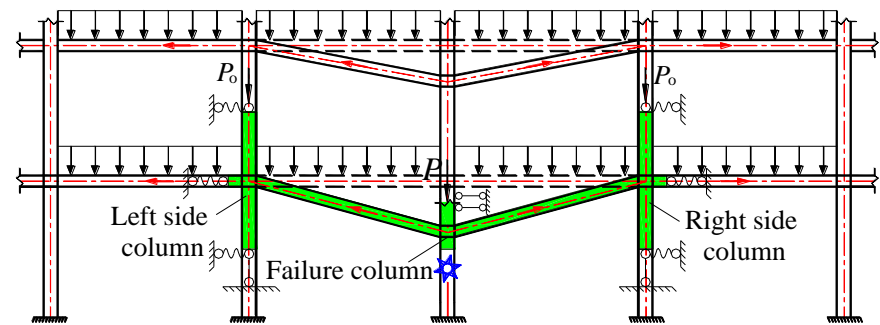

(a) Double-full-span subassembly

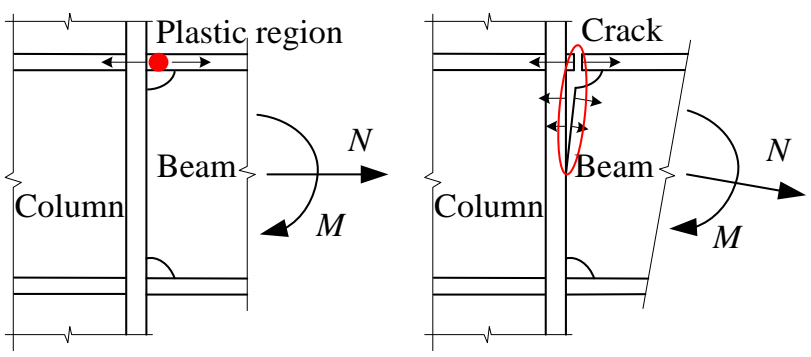

(b) Full welded connection
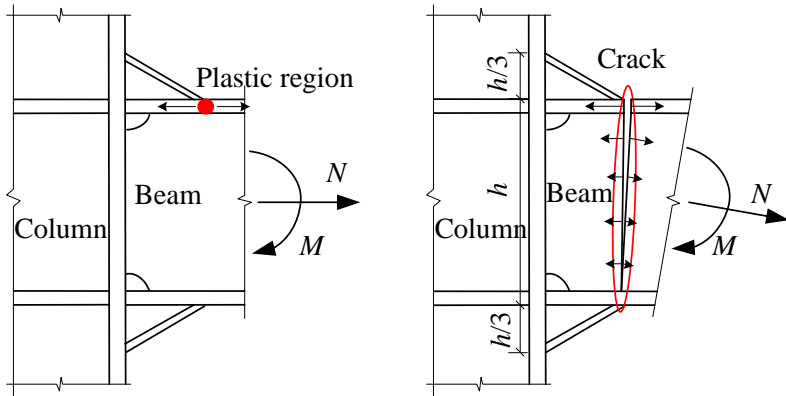

(c) Full-welded connection with axillary plates

Fig. 2 Failure modes of traditional joints

In this study, folded axillary plates are added the outer side of the beam-end flanges in an attempt to overcome the above shortcomings of traditional rigid connections, as shown in Fig. 3. The long and short legs of the folded axillary plate are connected to the beam and column flange, respectively, via slot welding to ensure a reliable connection. The aim of increasing the folded axillary plates is to enhance the ultimate deformation and bearing capacity of the structure against progressive collapse; thus avoiding premature brittle cracking at the beam end.

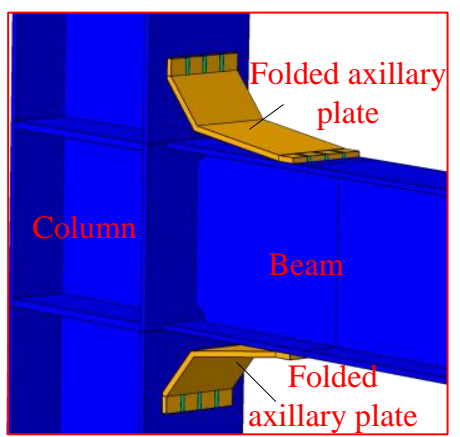

(a) 3D diagram

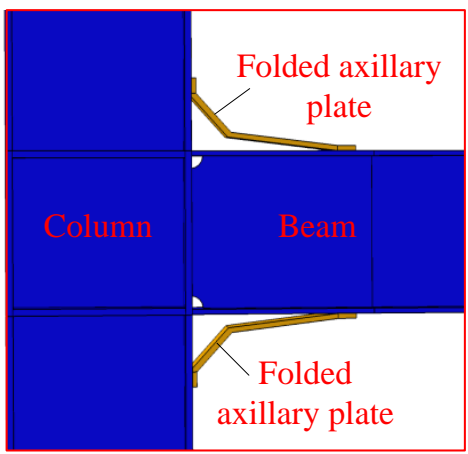

(b) Elevation 


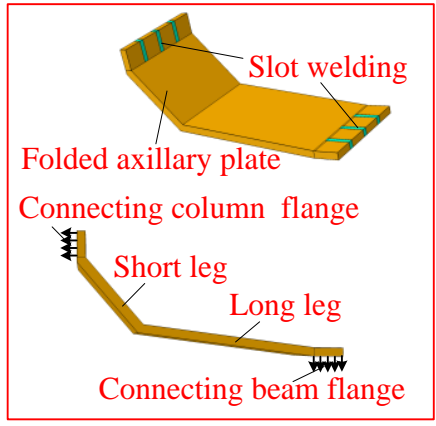

(c) Folded axillary plate

Fig. 3 Improved full-welded connection

\subsection{Working principle of substructure with folded axillary plates}

\subsubsection{Collapse-resistance target of substructure with folded axillary plates}

Generally, the resistance process of the beam-column substructure with full-welded connections, following the failure of the internal column, primarily involved the elastic stage $(\mathrm{OA})$ and the flexure-catenary mixed stage $(\mathrm{AB})$, as shown in the "TWC" curve in Fig. 4. At point B, the bearing capacity of the substructure was lost owing to the premature crack of the beam end weld or beam flange. In this study, folded axillary plates are added the outer side of the beam-end flanges in an attempt to make the deformation and resistance of the structure continue to develop on the basis of the original curve, ultimately resulting in the formation of the collapse resistance improved stage (BC), as shown in the "IWC" curve in Fig. 4. When the tension beam-end flange breaks, the substructure will not lose its bearing capacity immediately. At this time, the internal forces in the beam flange are transmitted by the folded axillary plates and the resistance of the substructure continues to grow until the folded axillary plate cracks. It should be noted that the formation of the "IWC" curve is closely related to the geometric parameters and mechanical properties of the folded axillary plate, which are analyzed and discussed in detail in Sections 4 and 5 of this paper.

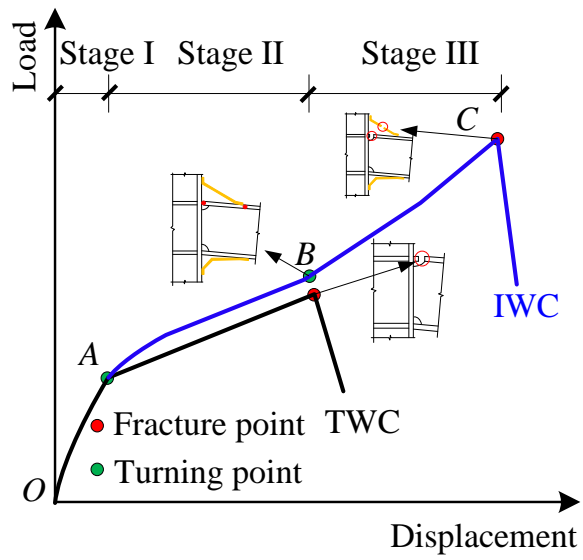

Fig. 4 Resistance curve

\subsubsection{Expected failure mode of substructure with folded axillary plates}

To achieve the collapse resistance improved target of the "IWC" curve in Fig. 4, the failure sequence of the substructure with folded axillary plates is expected to occur as follows. In the initial stage, the axial force of the joint is small and the folded axillary plate does not participate in the stress of the substructure. At the end of this stage (point A in Fig. 4), a plastic region appears in the flange at the beam root and the deformation of the joint is shown in Fig. 5 (a). Then, the substructure enters the flexure-catenary mixed stage and the axial force of the joint increases rapidly. At this time, the tension and compression folded axillary plates start to work, forming a certain bending moment to resist the external load. At the end of this stage (point B in Fig. 4), the folded axillary plate at the tension side is straightened and two plastic regions are developed at the beam-end flanges, as shown in Fig. 5 (b). With the increase in joint deformation, the substructure enters the collapse resistance improved stage. Two failure modes may occur owing to the different degrees of plastic development of the beam root and the location where the plastic hinge moves out, as shown in Fig. 5 (c). For failure mode I, the tension beam flange at the beam root cracks and then extends to the beam web. The folded axillary plate in tension gradually appears in the plastic zone and then begins to shrink or even break. For failure mode II, the tension beam flange breaks at the place where the plastic hinge moves out and then extends to the beam web. The folded axillary plate in compression is squeezed and its long leg gradually moves closer to the beam flange, as shown in Fig. 5 (c).

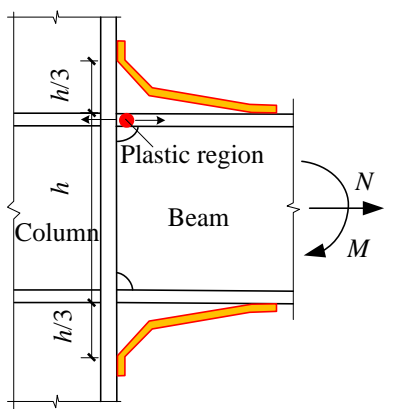

(a) Elastic stage

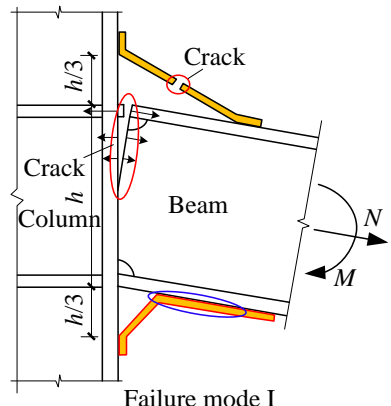

(c) Collapse-resistance improved stage

\subsubsection{Working mechanism of folded axillary plate}

The deformation of the folded axillary plate in the initial state is shown in Fig. 6 (a), and its shape is determined by parameters $a, b, l_{1}$, and $l_{2}$. For the fullwelded connection with axillary plates, to reduce the clearance requirements at the connection, FEMA-267 recommended parameter $a$ as $1 / 3 h$ and parameter $b$ as $0.5-0.6 h$ ( $h$ is the beam height) [24]. In this study, the parameter $a$ is assumed to be $1 / 3 h$ for the connection with the folded axillary plate. Parameter $b$ will affect the position of the plastic hinge moving out, and the elongation deformation of the folded axillary plate, as discussed in Section 5.4. If parameters $a$ and $b$ are selected and the lengths of $l_{1}$ and $l_{2}$ are determined, the shape of the folded axillary plate can be determined.

In the case of the beam-column substructure without the folded axillary plates, when the tension beam flange was broken, the beam-end rotation was defined as $\varphi_{0}$ in this study, which can be calculated according to Eq. (1). This could be determined according to existing tests and finite element analysis (FEA). In reference [17], it was suggested that when the tension beam flange of the substructure with full welded connections and welded unreinforced flangebolted web connections broke, the beam-end rotation $\varphi_{0}$ could be assumed to be $0.08-1.10 \mathrm{rad}$. For the substructure with the folded axillary plates, the beamend rotation is $\varphi$, as shown in Fig. 6 (b). To avoid the loss of resistance of the substructure with the folded axillary plates, owing to the crack of the tension beam-end flange, $\varphi=\varphi_{0}$ is assumed, the folded axillary plate is straightened and it starts to work in the stress of the developed substructure. The value of $\varphi_{0}$ is critical for determining the lengths of the short and long legs of the folded axillary plate. Therefore, the value of $\varphi_{0}$ should be determined before $l_{1}$ and $l_{2}$ are selected.

$\varphi_{0}=\arctan \frac{\delta}{L}$

where $\delta$ is the displacement of the middle column in the substructure without the axillary plates and $L$ is the beam length.

In the case of the folded axillary plate at the tension side, its short leg moves around the fixed point $M$ from point $A$ to $C$, and its long leg moves around the 
fixed point $O$ from point $B$ to $D$, as shown in Fig. 6 (b). According to the kinematic geometry relationship of the folded axillary plate at the tension side, the relationship equation between the design parameters $l_{1}$ and $l_{2}$ and the given parameters $a, b$, and $\varphi$ can be derived. The details are as follows:

The length of MD in triangle OMD can be determined based on the cosine theorem of triangles, as shown in Eq. (2).

$l_{\mathrm{MD}}^{2}=a^{2}+b^{2}-2 a b \cos \left(\varphi_{0}+90^{\circ}\right)=a^{2}+b^{2}+2 a b \sin \varphi_{0}$

Based on the cosine theorem of triangles, the length of BD in triangle OBD can be obtained, as shown in Eq. (3).

$l_{\mathrm{BD}}=\sqrt{2} b \sqrt{1-\cos \varphi_{0}}$

The angle MBD of triangle MBD can be obtained via the cosine theorem of triangles, following which Eqs. (2) and (3) are substituted into Eq. (4).

$$
\begin{aligned}
& \angle M B D=\arccos \frac{l_{\mathrm{MB}}^{2}+l_{\mathrm{BD}}^{2}-l_{\mathrm{MD}}^{2}}{2 l_{\mathrm{MB}} \cdot l_{\mathrm{BD}}} \\
& =\arccos \frac{b-b \cos \varphi_{0}-a \sin \varphi_{0}}{\sqrt{2} \sqrt{a^{2}+b^{2}} \sqrt{1-\cos \varphi_{0}}}
\end{aligned}
$$

In triangle $\mathrm{ABD}$, the length of $\mathrm{AD}$ can be obtained based on the cosine theorem of triangles, as shown in Eq. (5).

$l_{\mathrm{AD}}^{2}=l_{\mathrm{AB}}^{2}+l_{\mathrm{BD}}^{2}-2 l_{\mathrm{AB}} \cdot l_{\mathrm{BD}} \cos \angle A B D$

$=l_{\mathrm{AB}}^{2}+l_{\mathrm{BD}}^{2}-2 l_{\mathrm{AB}} \cdot l_{\mathrm{BD}} \cos \left(\angle M B D-\theta_{2}\right)$

Similarly, in triangle BMD, the angle BMD can be obtained via the cosine theorem of triangles, following which Eqs. (2) and (3) are substituted into Eq. (6). In triangle DMA, the length of $\mathrm{AD}$ can be obtained via the cosine theorem of triangles, as shown in Eq. (7).

$$
\begin{aligned}
& \angle B M D=\arccos \frac{l_{\mathrm{MB}}^{2}+l_{\mathrm{MD}}^{2}-l_{\mathrm{BD}}^{2}}{2 l_{\mathrm{MB}} \cdot l_{\mathrm{MD}}} \\
& =\arccos \frac{a^{2}+a b \sin \varphi_{0}+b^{2} \cos \varphi_{0}}{\sqrt{a^{2}+b^{2}} \sqrt{a^{2}+b^{2}+2 a b \sin \varphi_{0}}}
\end{aligned}
$$

$l_{\mathrm{AD}}^{2}=l_{\mathrm{MD}}^{2}+l_{\mathrm{MA}}^{2}-2 l_{\mathrm{MD}} \cdot l_{\mathrm{MA}} \cos D M A$

$=l_{\mathrm{MD}}^{2}+l_{\mathrm{MA}}^{2}-2 l_{\mathrm{MD}} \cdot l_{\mathrm{MA}} \cos \left(\theta_{1}-\angle B M D\right)$

By combining Eqs. (5) and (7), the functional equation of parameters $l_{1}$ and $l_{2}$ with respect to $a, b$, and $\varphi_{0}$ can be obtained; that is, the values of parameters $l_{1}$ and $l_{2}$ satisfy Eq. (8).

$F\left(l_{1}, l_{2}\right)=g\left(a, b, \varphi_{0}\right)$

$=l_{1}^{2}-l_{2}^{2}+a^{2}-b^{2}+2 a b \sin \varphi_{0}+2 b^{2} \cos \varphi_{0}$

$+2 \sqrt{2} l_{2} b \sqrt{1-\cos \varphi_{0}} \cos \angle A B D$

$-2 l_{1} \sqrt{a^{2}+b^{2}+2 a b \sin \varphi_{0}} \cos \angle D M A=0$

where,

$$
\angle A B D=\arccos \frac{b-b \cos \varphi_{0}-a \sin \varphi_{0}}{\sqrt{2} \sqrt{a^{2}+b^{2}} \sqrt{1-\cos \varphi_{0}}},
$$

$$
-\arccos \frac{l_{2}^{2}+a^{2}+b^{2}-l_{1}^{2}}{2 l_{2} \sqrt{a^{2}+b^{2}}}
$$

$\angle D M A=\arccos \frac{l_{1}^{2}+a^{2}+b^{2}-l_{2}^{2}}{2 l_{1} \sqrt{a^{2}+b^{2}}}$

$-\arccos \frac{a^{2}+a b \sin \varphi_{0}+b^{2} \cos \varphi_{0}}{\sqrt{a^{2}+b^{2}} \sqrt{a^{2}+b^{2}+2 a b \sin \varphi_{0}}}$
The short leg of the folded axillary plate on the compression side moves around the fixed point $N$ from point $E$ to $G$ and its long leg moves around the fixed point $O$ ' from point $F$ to $H$, as shown in Fig. 6(b). If the values of the initial design parameters $l_{1}$ and $l_{2}$ are unreasonable, point $G$ will cross O'F and $\mathrm{O}^{\prime} \mathrm{H}$, which is not in line with the actual situation. To avoid this situation, the distance from point $G$ to O'F in the initial stage should be greater than 0 , so that Eq. (9) is satisfied. At the same time, when the beam-end rotation is $\varphi_{0}$, the distance DG from point $G$ to O'H should be greater than 0 . If the angle O'NG $=\beta$, the coordinates of points $G$ and $H$ are $\left(l_{1} \sin \beta,-a+l_{1} \cos \beta\right)$ and $\left(b \cos \varphi_{0}\right.$, $\left.b \sin \varphi_{0}\right)$, respectively. The distance from point $G$ to O'H is DG, as shown in Eq (10). Then, Eq. (11) can be obtained by simplifying Eq. (10).

$$
\begin{aligned}
& l_{1}<\frac{a}{\cos \left(\arctan (a / b)-\theta_{1}\right)} \\
& d_{\mathrm{G}}=\frac{\left|l_{1} \tan \varphi_{0} \sin \beta-a+l_{1} \cos \beta\right|}{\sqrt{1+\tan ^{2} \varphi_{0}}}>0
\end{aligned}
$$

$$
l_{1}<\frac{a}{\tan \varphi_{0} \sin \beta+\cos \beta}
$$

$\beta$ needs to be solved in Eq. (11), which can be obtained from Eq. (15). The specific derivation is as follows:

The length of the $\mathrm{NH}$ in the triangle $\mathrm{FNH}$ is obtained via the cosine theorem of triangles, as shown in Eq. (12).

$l_{\mathrm{NH}}^{2}=a^{2}+b^{2}-2 a b \cos \left(90^{\circ}-\varphi_{0}\right)=a^{2}+b^{2}-2 a b \sin \varphi_{0}$

Based on the cosine theorem of triangles, the angle $\mathrm{O}^{\prime} \mathrm{NH}$ in triangle $\mathrm{O}$ ' $\mathrm{NH}$ can be obtained, as shown in Eq. (13).

$$
\begin{aligned}
& \angle O^{\prime} N H=\arccos \frac{l_{\mathrm{O}^{\prime} \mathrm{N}}^{2}+l_{\mathrm{NH}}^{2}-l_{\mathrm{O}^{\prime} \mathrm{H}}^{2}}{2 l_{\mathrm{O}^{\prime} \mathrm{N}} \cdot l_{\mathrm{NH}}} \\
& =\arccos \frac{a-b \sin \varphi_{0}}{\sqrt{a^{2}+b^{2}-2 a b \sin \varphi_{0}}}
\end{aligned}
$$

In the triangular $\mathrm{NGH}$, the length of $\mathrm{GH}$ can be obtained via the cosine theorem of triangles. When the folded axillary plate is compressed, the length $l_{2}$ of the long leg is equal to the length of GH, as shown in Eq. (14).

$l_{\mathrm{GH}}^{2}=l_{\mathrm{NG}}^{2}+l_{\mathrm{NH}}^{2}-2 l_{\mathrm{NG}} \cdot l_{\mathrm{NH}} \cos \angle G N H$

$=l_{\mathrm{NG}}^{2}+l_{\mathrm{NH}}^{2}-2 l_{\mathrm{NG}} \cdot l_{\mathrm{NH}} \cos \left(\angle O^{\prime} N H-\beta\right)=l_{2}^{2}$

If Eqs. (12) and (13) are introduced into Eq. (14), the calculation formula for angle $\beta$ can be obtained, as shown in Eq. (15).

$$
\begin{gathered}
\beta=\arccos \frac{a-b \sin \varphi_{0}}{\sqrt{a^{2}+b^{2}-2 a b \sin \varphi_{0}}} \\
-\arccos \frac{l_{1}^{2}-l_{2}^{2}+a^{2}+b^{2}-2 a b \sin \varphi_{0}}{2 l_{1} \sqrt{a^{2}+b^{2}-2 a b \sin \varphi_{0}}}
\end{gathered}
$$

When the beam-column substructure with the folded axillary plates enters the collapse resistance improved stage, two failure modes may occur because of the different degrees of plastic development of the beam root and the point where the plastic hinge moves out. The anti-collapse performance of the substructure in this stage is also related to the width and thickness of the folded axillary plate, as discussed in Section 5. When the tension beam flange was broken, the force in the tension beam flange was mainly transmitted by the folded axillary plate. In this case, according to the balance relationship between the folded axillary plate and the tension beam flange, when the thickness of the folded axillary plate was determined, its width could be calculated according to Eq. (16).

$w=\frac{b b_{\mathrm{f}} t_{\mathrm{f}} f_{\mathrm{bu}}}{f_{\mathrm{u}} t \sqrt{a^{2}+b^{2}}}$ 
where $t_{\mathrm{f}}$ is the thickness of the beam flange, $b_{\mathrm{f}}$ is the width of the beam flange, $f_{\mathrm{bu}}$ is the tensile strength of the beam flange, $f_{\mathrm{u}}$ is the tensile strength of the folded axillary plate and $t$ is the thickness of the folded axillary plate.

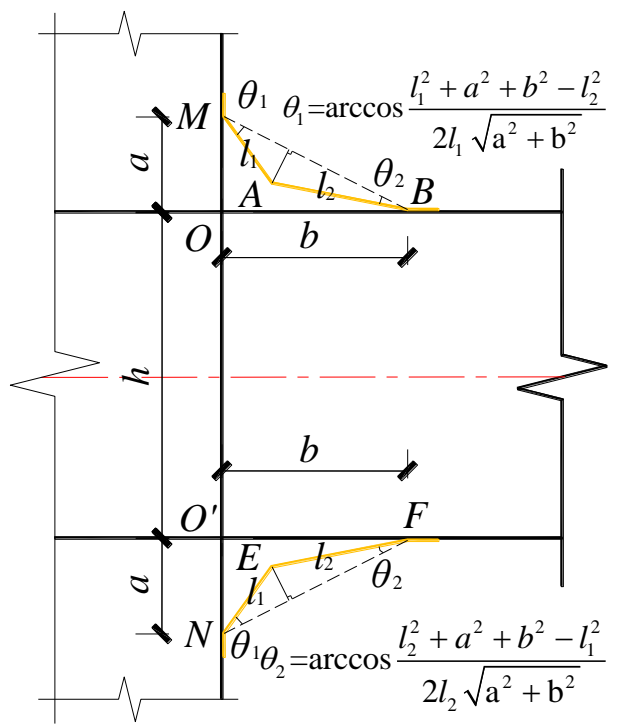

(a) Before deformation

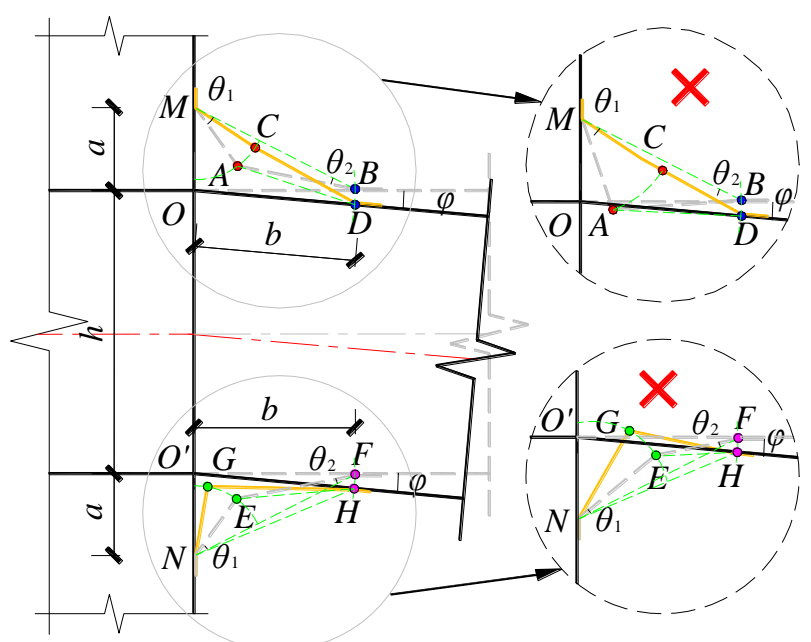

(b) After deformation

Fig. 6 Working mechanism of improved full welded connection

\subsubsection{Design process of folded axillary plate}

Reasonable design of the folded axillary plate is the key to enhance the ultimate deformation and bearing capacity of the structure with full welded connections with folded axillary plates, at the same time. The design of the folded axillary plate includes seven parameters: $\varphi_{0}, a, b, l_{1}, l_{2}, t$, and $w . \varphi_{0}$ is defined as the beam-end rotation of the substructure, without the folded axillary plate, when the tension beam flange breaks at the root of the beam. This can be determined by existing tests and FEA. In this study, parameter $a$ is recommended to be $1 / 3 h$ for the folded axillary plate. The parameter $b$ affects the position of the plastic hinge moving outward, and its value is discussed in Section 5.4. If $l_{2}$ is initially selected, $l_{1}$ can be calculated using Eq. (8) and should satisfy Eqs. (9) and (11): The thickness of the folded axillary plate is discussed in Section 5.1. Subsequently, the width of the folded axillary plate $w$ can be calculated using Eq. (16).

The design process of the folded axillary plate is as follows: (1) first, the beam-end rotation $\varphi_{0}$ of the substructure with full welded connection is determined; (2) parameters $a, b, t$, and $l_{2}$ are initially selected; (3) length $l_{1}$ of the short leg of the folded axillary plate is calculated according to Eq. (8); (4) the value of $l_{1}$ is checked to determine whether it satisfies the requirements of Eqs. (9) and (11); (5) the width of the folded axillary plate is calculated using Eq. (16) according to the thickness of the folded axillary plate selected in (2). The specific design process is shown in Fig. 7.

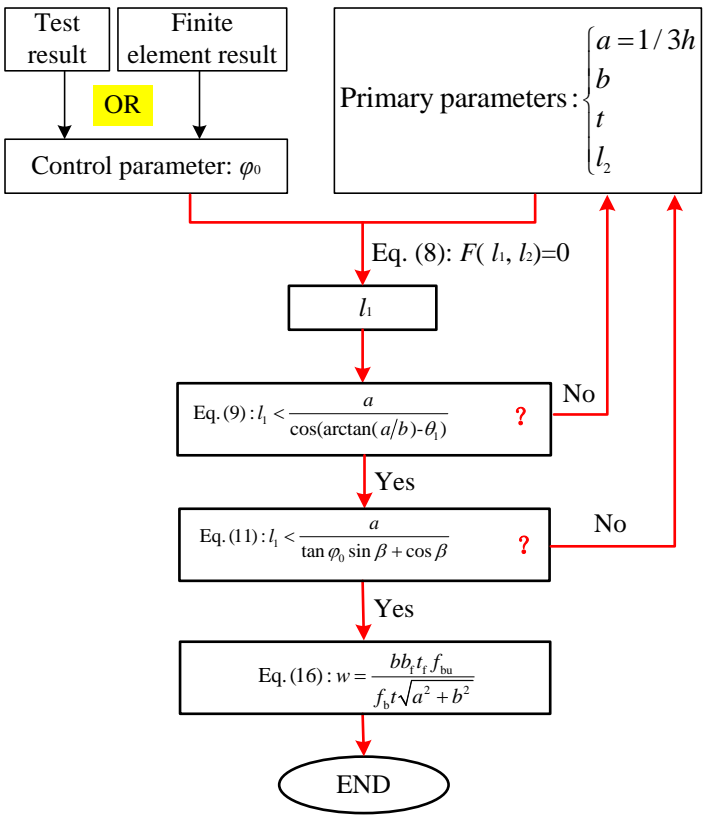

Fig. 7 Design process of folded axillary plate

\section{Verification of finite element model}

To verify the accuracy of the finite element model, the double-full-span beam-column substructure test conducted by Lew et al. [25] was selected, as shown in Fig. 8(a). The selected beam-column connection was the welded unreinforced flange-bolted web connection. According to the section and geometric dimensions of the beam and column components in the literature [25], a finite element model of the test specimen was built, as shown in Fig. 8(b). Based on the boundary conditions of the substructure in the test, the upper end of the side column was hinge-restrained, that is, $\mathrm{U} 1=\mathrm{U} 2=\mathrm{U} 3=0$ and the lower end of the side column was restrained, that is, $\mathrm{U} 1=\mathrm{U} 2=\mathrm{U} 3=\mathrm{UR} 1=\mathrm{UR} 2=\mathrm{UR} 3$ $=0$. To ensure vertical movement of the failure column, U1 and U2 at the upper and lower ends of the failure column were constrained. The beam, column, shear plate, and bolt adopted solid elements (C3D8R). The beam flanges and shear plate were connected to the column flange using the "tie" command in ABAQUS. The contact relationship between the bolt and the beam web and shear plate was set as the general contact. The Coulomb friction contact was utilized in the tangential direction and the friction coefficient was 0.3 . The normal direction was set as a hard contact. To decrease the effect of mesh sensitivity on steel fracture, a mesh of $5 \mathrm{~mm}$ in size was adopted at the shear plate, bolt, and beam end in the connection area. A $30 \mathrm{~mm}$ grid was adopted for the rest of the column and beam. The constitutive relation and fracture parameters of steel are detailed in reference [25]. The displacement-controlled loading method was adopted at the top of the failure column until the bearing capacity of the specimen was lost. The explicit dynamic quasi-static method was used to simulate the failure process of the substructure. During loading, no significant dynamic effect was introduced to maintain that the simulation process was static, i.e., the kinetic energy of the structural system during the simulation loading process was kept within $10 \%$ of its internal energy [26].

Fig. 9(a) shows a comparison between the numerical simulation data and the test results for the load-displacement curve of the model specimen designed by Sadek et al. [25]. The numerical simulation results were in good agreement with the experimental results. Owing to the limited loading range of the test, the test specimen had to be unloaded when the displacement of the middle column was approximately 475 $\mathrm{mm}$ and then loaded again. However, the numerical simulation did not unload but continued loading the specimen until failure. Fig. 9(b) shows the damage mode of the numerical simulation of the specimen, which is consistent with the test failure mode in Fig. 8(a). Both failures were due to the first fracture of the tension beam-end flange, which resulted in a sudden decrease in the resistance of the specimen. Above all, the numerical simulation method can accurately simulate the resistance of the specimen and its damage mode. 

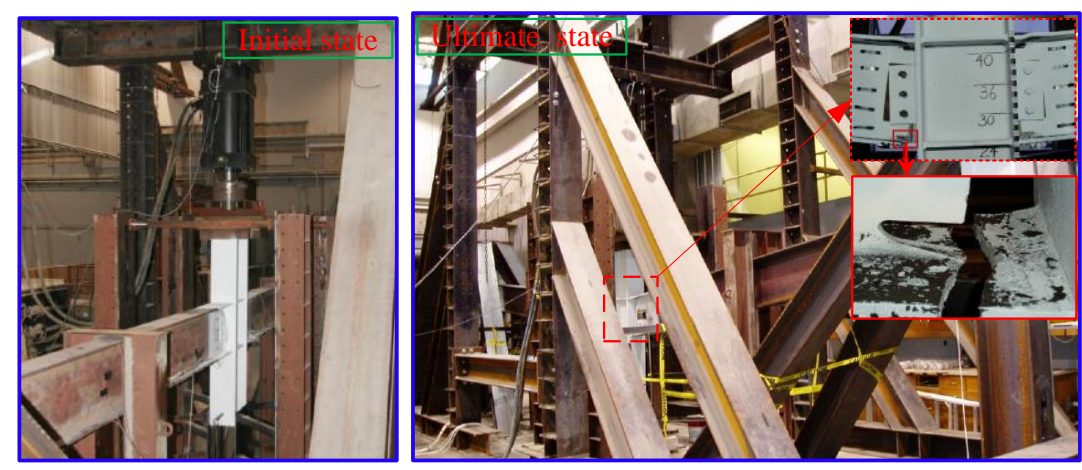

(a) Tested steel frame [25]

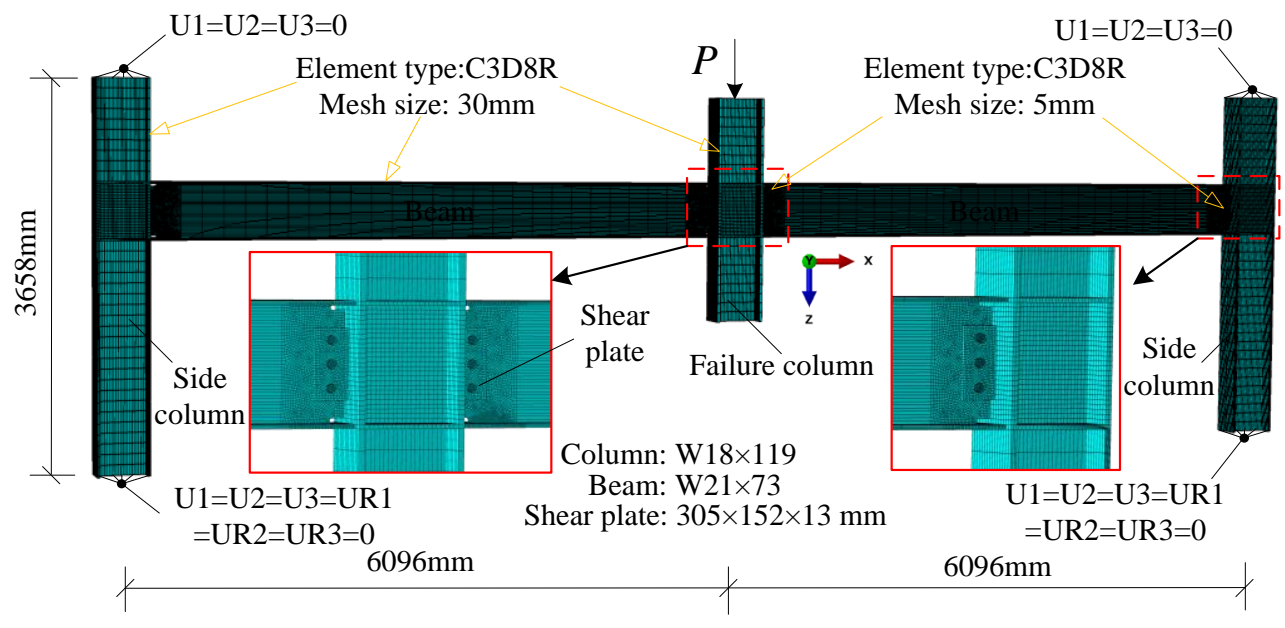

(b) 3-D numerical model

Fig. 8 Validated numerical model

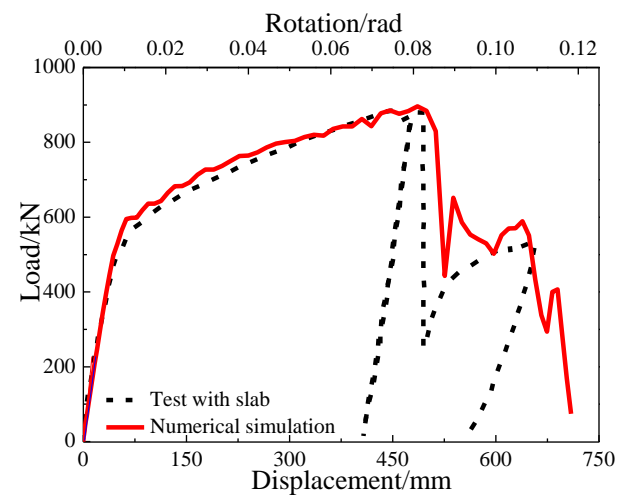

(a) Load-displacement curves

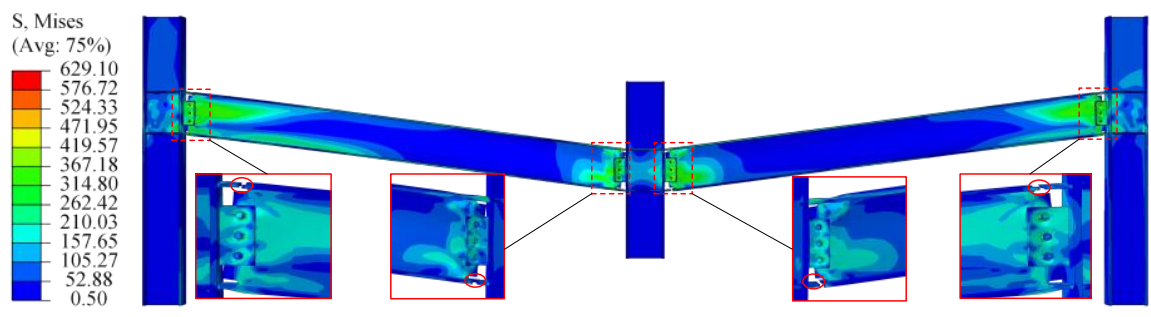

(b) Failure model

Fig. 9 Results of the numerical model

\section{Anti-collapse behavior of the improved connection}

\subsection{Specimen design}

Three model specimens with different connection forms were designed. The three types of connections were fully welded (FW), fully welded with axillary plates (FWA), and fully welded with folded axillary plates (FWFA); their details are shown in Fig. 10. According to the symmetry of the double-full-span beam-column substructure in Fig. 2, 1/4 of the model specimen was selected [27,28], as shown in Fig. 11(a). H $450 \mathrm{~mm} \times 200 \mathrm{~mm} \times 9 \mathrm{~mm} \times 14 \mathrm{~mm}$ and $\mathrm{H} 500 \mathrm{~mm} \times 300 \mathrm{~mm} \times$ $11 \mathrm{~mm} \times 18 \mathrm{~mm}$ were selected for the sections of the beam and column, respectively. According to the design process of the folded axillary plate in Fig. (7), the parameters of the folded axillary plate in the FWFA connection met the requirements of Eqs. (8), (9), (11), and (16) in Section 2, as shown in Fig. 10. All members contained Q235 steel and the constitutive relation of the steel was simplified, as shown in Fig. 11(b) [29]. The fracture parameters of Q235 steel as per reference [30] were adopted for the three model specimens. To consider the ax ial restraint of the peripheral members of the substructure on the beam end, a boundary axial spring was considered in the numerical model, as shown in Fig. 11(a), and its elastic stiffness was assumed to be the axial stiffness of the steel beam. The symmetry plane of the failure column was restrained, that is, U1 = $\mathrm{UR} 2=\mathrm{UR} 3=0$. The end of the beam was set as hinged, i.e., $\mathrm{U} 2=\mathrm{U} 3=0$. The grid size of the beam, column, and folded axillary steel plates was approximately $5 \mathrm{~mm}$. A pushdown load with displacement-controlled was applied slowly to the top of the middle column. The loading process was terminated until the model specimen was damaged.

\subsection{Performance analysis of subassemblies}

Fig. 12(a) presents the vertical load versus the displacement of the middle column of the three specimens. In the initial stage, the stiffnesses of the three specimens were essentially the same. As the displacement of the middle column increased, 
the specimens entered the flexure-catenary mixed phase. The load of the FWA, FWFA, and FW specimens successively decreased. Subsequently, the load of the specimen FW dropped suddenly owing to the fracture of the beam flange. This indicated that $\varphi_{0}$ was $0.083 \mathrm{rad}$. However, the loads of the FWA and FWFA specimens continued to develop owing to the load transfer of the axillary plate. When compared to the FW specimen, the FWA and FWFA specimens could attain improved collapse resistance; the maximum resistance and corresponding deformation of the FWA specimen could be increased by $75.7 \%$ and $53.2 \%$, respectively. The maximum resistance and corresponding deformation of the FWFA specimen could be increased by $169.7 \%$ and $129.6 \%$, respectively. However, compared to the FWA specimen, the FWFA specimen demonstrated a greater resistance and deformation via the folded axillary plates. Its maximum resistance and corresponding deformation could be increased by $53.5 \%$ and $49.9 \%$, respectively.

Figs. 12 (b) and 12(c) show the moments at Sections S0 and S1, respectively, versus the displacement of the middle column. For the FW specimen, the development trends of the bending moments at Sections S0 and S1 were similar; these were halted owing to the crack of the tension beam-end flange. With regard to FWA specimen, the development trends of the bending moments in Sections S0 and S1 were different. This was because the upper and lower axillary plates at Section S0 would also form a bending moment to resist the load; hence, the bending moment of the FWA specimen was smaller than that of the other two model specimens, as shown in Fig. 12(b). With regard to FWFA specimen, given that the folded axillary plate does not participate in the stress of the substructure in the initial phase, the bending moment of the beam end was the same as that of the FW specimen. With the increase of the middle column deformation, the folded axillary plate gradually participated in the stress of the substructure, which caused the bending moment at the beam end to continue to develop, compared with the FW specimen. Finally, the development of the bending moments was terminated owing to the fracture of the beam-end flange and folded axillary plate.

Figs. 12(d) and 12(e) show the curves of the axial force in the beam at Sections S0 and S1, respectively. Fig. 12(f) shows the curves of the axial force transmitted by the upper and lower axillary plates. With regard to FW specimen, the axial force of each section in the beam was equal. With regard to FWA substructure, the beam axial force at Section S0 was greater than that in Section S1 before the specimen obtained the maximum bearing capacity. This indicates that the axial compressive force was transmitted in the upper and lower axillary plates. Subsequently, the total axial force in the upper and lower axillary plates was transformed from compression to tension. Finally, the development of the beam axial force was stopped owing to the fracture of the beam-end flange in Section S1. With regard to the FWFA substructure, the beam axial force at Section S0 was less than that in Section S1, until the substructure lost its main load. This indicates that part of the axial tensile force was transmitted by the upper and lower folded axillary plates. Compared to that of the FW and FWA specimens, the axial force in the beam of the FWFA specimen could attain the yield value, which indicates that the catenary action can be fully played out under the large deformations.

Additionally, according to the design principle of the folded axillary plate shown in Section 2, the folded axillary plate does not significantly affect the stress of the structure at small deformations and will greatly improve the ultimate deformation and resistance of the structure with FWFA connections at later stages. The substructure realized the collapse resistance improved stage by the folded axillary plates. Then, the catenary mechanism is fully played out and the beam performance is fully utilized.

Fig. 13 shows final failure states of the three model specimens with different connections. For the FW specimen, the first mode involved the tension beam flange at the beam root being broken, followed by the beam web gradually fracturing, as shown in Fig. 13(a). With regard to the FWA specimen, the plastic hinge at the beam root first moved outward, following which the beam flange and web at Section S1 broke successively, as shown in Fig. 13(b). With regard to the FWFA specimen, the folded axillary plate on the tension side was first gradually straightened, following which the folded axillary plate on the compression side gradually moved closer to the beam flange. Then, the two plastic regions formed at Sections S0 and S1 of the tension beam flange. With an increase in the connection deformation, the tension beam flange at the beam root breaks, followed by the folded axillary plate, as shown in Fig. 13(c), which is consistent with the expected damage mode I in Fig. 5.

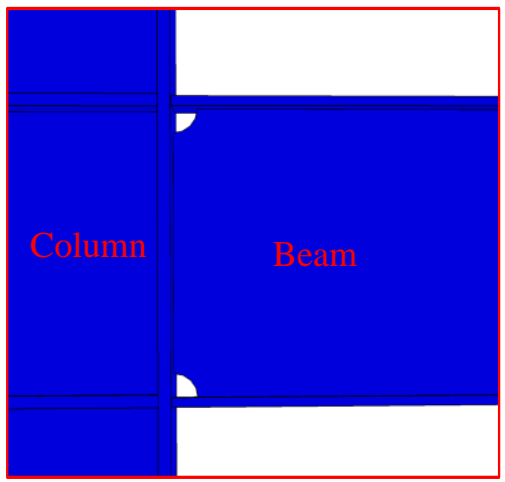

(a) FW connection

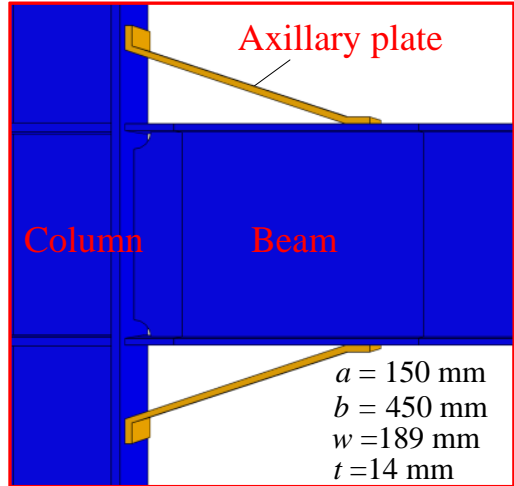

(b) FWA connection

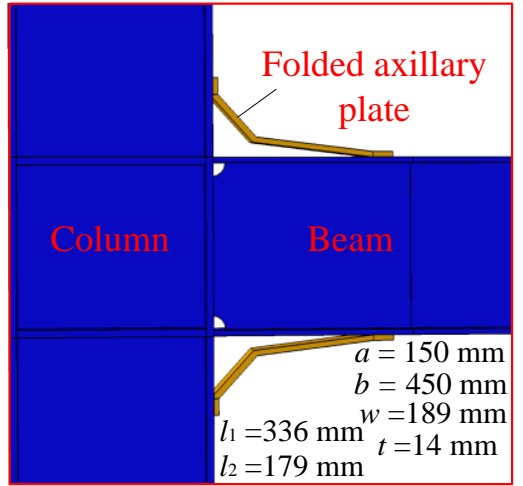

(c) FWFA connection

Fig. 10 Improved full welded connection
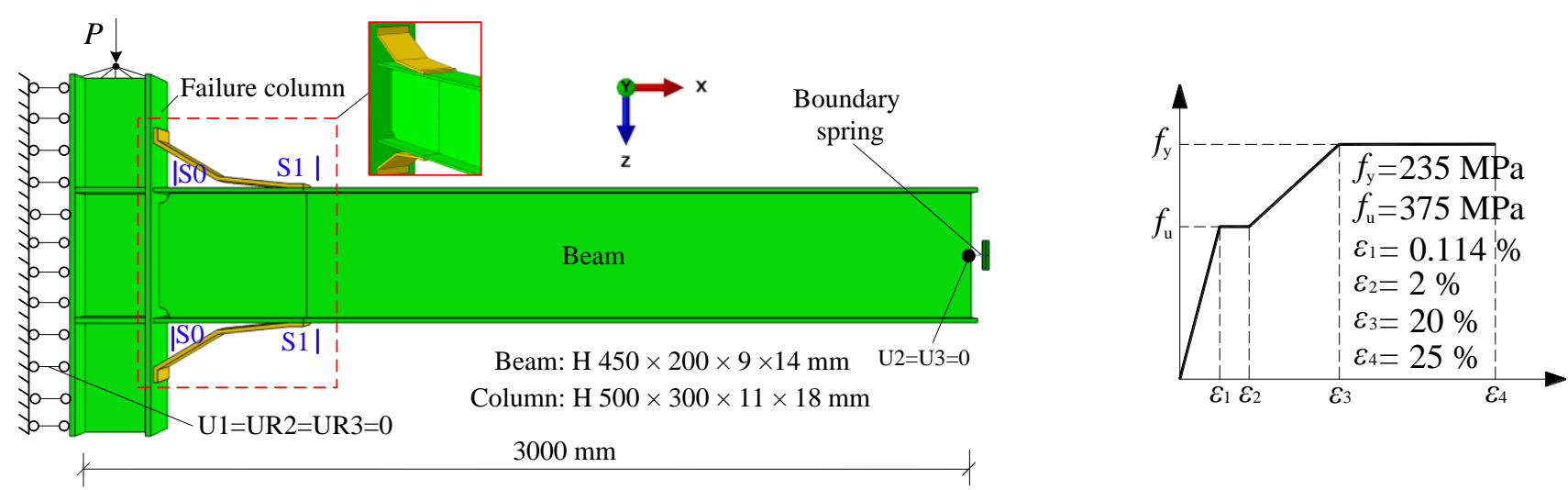

(a) $1 / 4$ substructure model

(b) Stress-strain relationship of steel [29]

Fig. 11 Numerical model for substructure with folded axillary plates 


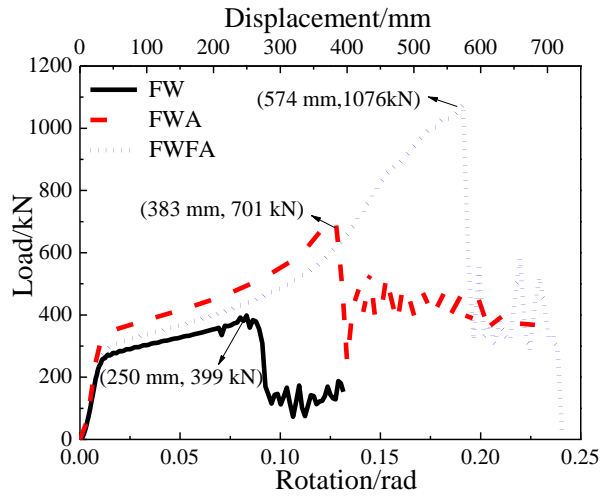

(a) Load vs. displacement

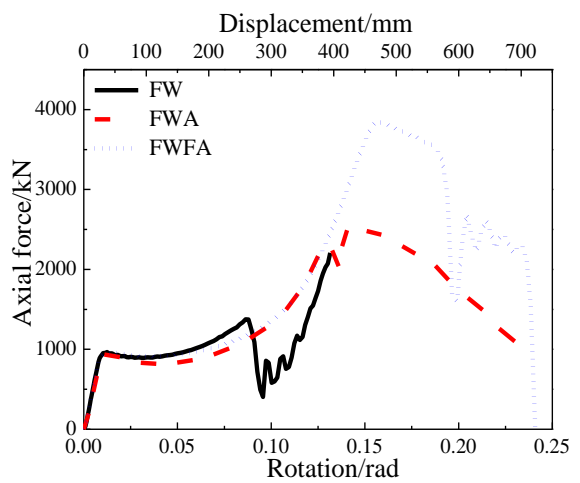

(d) Axial force in beam at Section S0

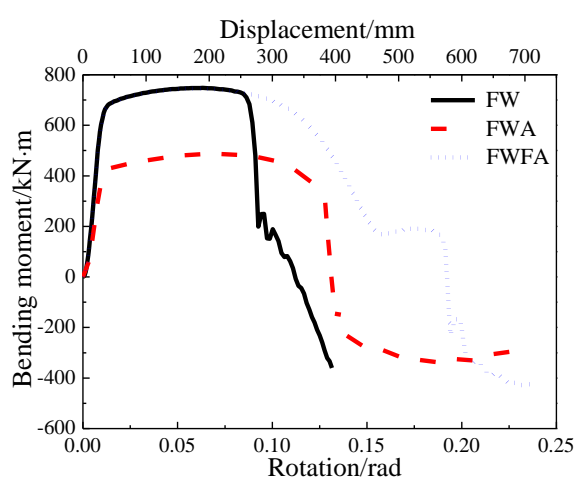

(b) Bending moments at Section S0

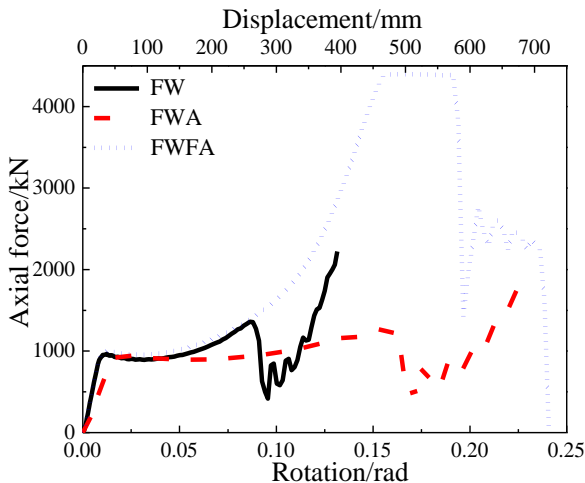

(C) Axial force in beam at Section S1

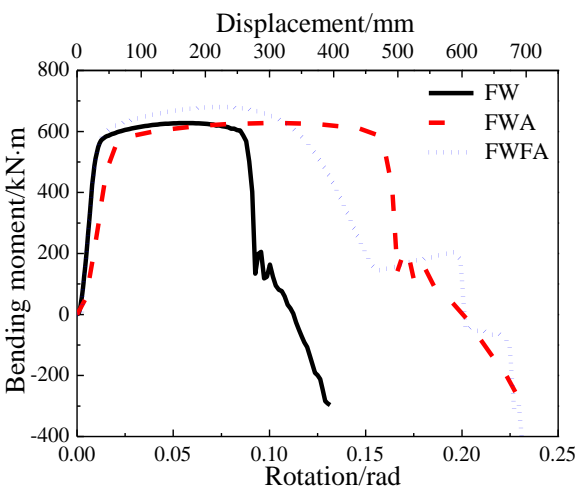

(c) Bending moments at Section S1

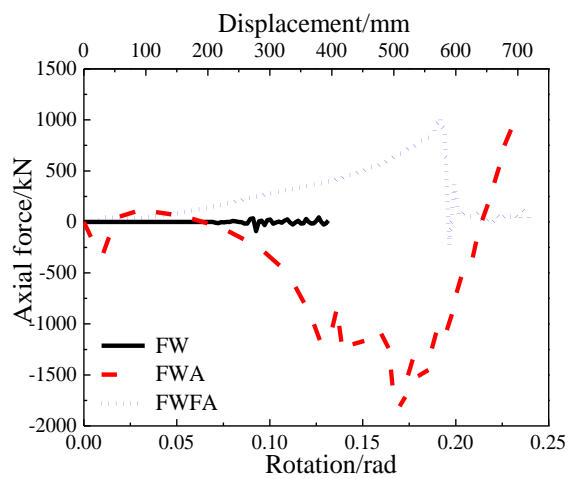

(f) Axial force in axillary plates

Fig. 12 Performance analysis results of subassemblies
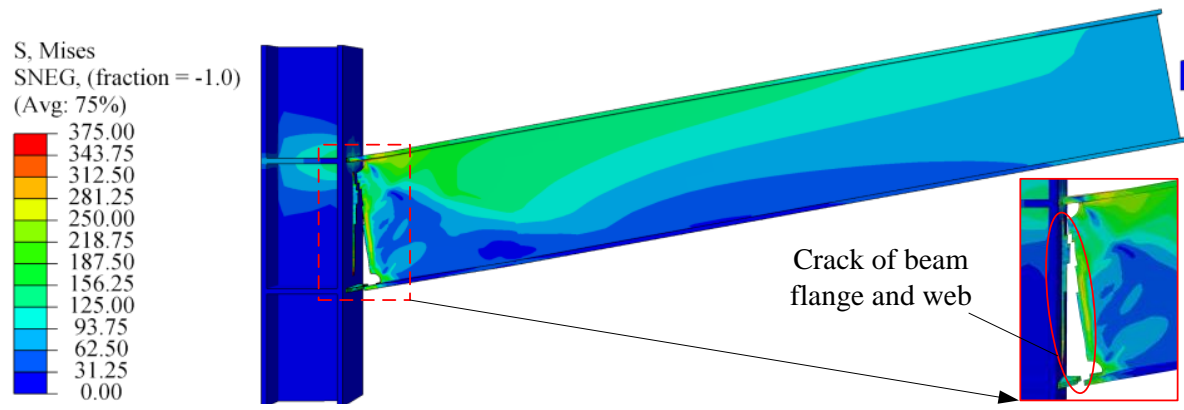

(a) Final failure state of FW connection

$\mathrm{S}$, Mises

SNEG, (fraction $=-1.0$ )

(Avg: 75\%)
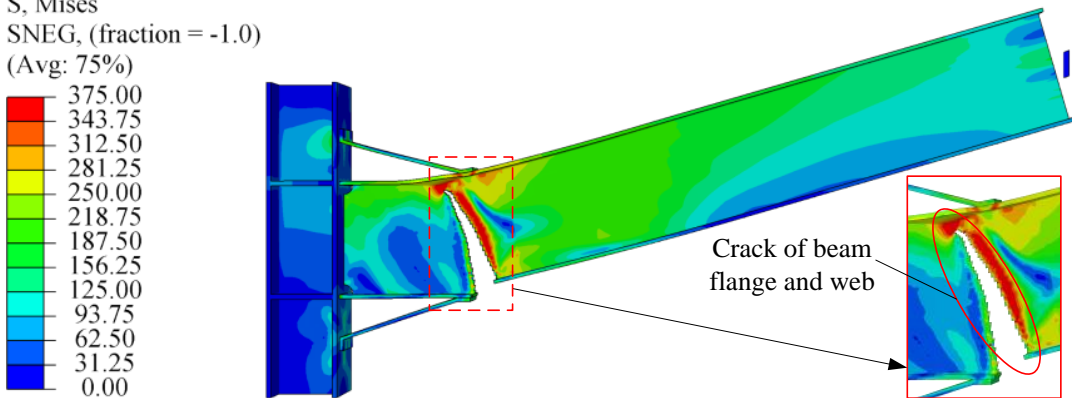

(b) Final failure state of FWA connection 


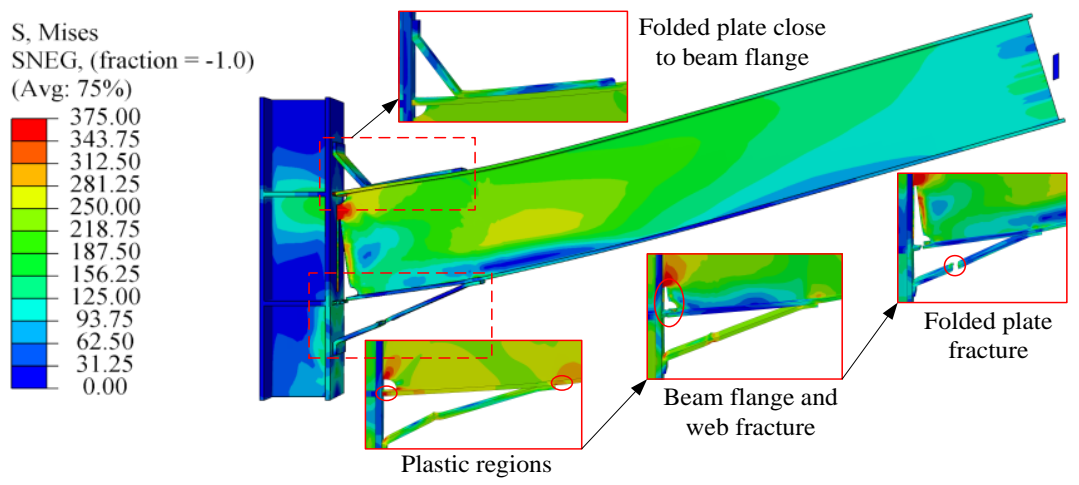

(c) Final failure state of FWFA connection

Fig. 13 Final failure states of connections

\section{Parameter study}

\subsection{Thickness of folded axillary plate}

To investigate the effect of the thickness of the folded axillary plate on anti-collapse behavior of the beam-column substructure with the FWFA connection, five model specimens were selected and analyzed. The thicknesses of the folded axillary plates were 6, 10, 14, 18, and $22 \mathrm{~mm}$. Fig. 14(a) depicts the load-displacement curves of the specimens. Except for the specimen with a $6 \mathrm{~mm}$ thick folded axillary plate, all other specimens achieved collapse resistance improvement by the folded axillary plate. The maximum resistance and corresponding deformation were close to 1070 and $574 \mathrm{~mm}$, respectively. For the specimen with a $6 \mathrm{~mm}$ thick folded axillary plate, when the tension flange at the beam root was broken, the folded axillary plate broke immediately due to the thin folded axillary plate, reducing the collapse resistance. Therefore, the thickness of the folded axillary plate should not be too small. When the folded axillary plate is too thick, the process appears uneconomical; however, relatively large initial imperfections may be generated in the process of manual bending. Therefore, it is suggested to assume $0.75-1.0 t_{\mathrm{f}}$ as the thickness of the folded axillary plate.

\subsection{Width of the folded axillary plate}

Five specimens were selected to study the effect of the width of the folded axillary plate on the anti-collapse behavior of the substructure with the FWFA connection. The widths of the folded axillary plate were 120, 140, 160, 180, and $200 \mathrm{~mm}$. Fig. 14(b) depicts the load-displacement curves of the five model specimens. With the increase in the width of the folded axillary plate, the displacement and load of the specimens gradually increased. The failure mode first involved the tension beam flange being damaged, followed by the broken folded axillary plate. The failure sequence of the substructure with folded axillary plates involved the folded axillary plate on the tension side first gradually straightening, followed by the two plastic regions forming at the beam flange. Subsequently, either the tension beam flange at the beam root and the folded axillary plate broke successively or the tension beam flange broke at the location where the plastic hinge moved outward. For all specimens, the folded axillary plates improved the collapse resistance. Therefore, when the thickness of the folded axillary plate is determined, its width should meet the requirement of Eq. (16).

\subsection{Ratio of $l_{1} / l_{2}$}

To investigate the influence of the ratio of long to short leg on the collapse resistance of the substructure with the FWFA connection, five specimens were designed according to the design process of the folded axillary plate in Fig. 7. The lengths of the short and long leg of the five model specimens were selected, as shown in Table 1, which met the requirements of Eqs. (8), (9), (11), and (16). The loaddisplacement curves of the five model specimens are shown in Fig. 14(c). The five specimens can realize the collapse resistance improvement and their final failure states are similar, as shown in Fig. 13(c). However, when the ratio of $l_{1} / l_{2}$ is larger, the specimen will obtain a larger bearing capacity and deformation.

Table 1

Model specimens on the ratio of $l_{1} / l_{2}$

\begin{tabular}{cccccc}
\hline Specimens & FWFA-R1 & FWFA-R2 & FWFA-R3 & FWFA-R4 & FWFA-R5 \\
\hline$l_{1}(\mathrm{~mm})$ & 179 & 170 & 160 & 150 & 140 \\
$l_{2}(\mathrm{~mm})$ & 336 & 345 & 355 & 365 & 375 \\
$l_{1} / l_{2}$ & 0.533 & 0.493 & 0.451 & 0.411 & 0.374 \\
\hline
\end{tabular}

\subsection{Parameter $b$}

To study the effect of parameter $b$ of the folded axillary plate on the anti-collapse behavior of the structure with the FWFA connection, five specimens were designed according to the content in Section 2.2.3, with parameters $b$ of 300, 350, 400, 450, and $500 \mathrm{~mm}$. When parameter $b$ changes, with $l_{1}$ unchanged, $l_{2}$ will change accordingly. Fig. 15(a) depicts the load-displacement curves of the five model specimens. Compared to the specimen with a FW connection, the five specimens can achieve a collapse resistance improvement. With the increase in parameter $b$, the maximum load and deformation will increase initially and then decrease. In particular, when parameter $b$ is greater than $1.0 h$, the maximum resistance of the model specimen will be significantly reduced. Therefore, it is suggested that parameter $b$ is assumed to be $0.7-1.0 h$. Additionally, when the value of parameter $b$ is greater than or equal to 1.0 $h$, damage mode I will occur, as shown in Fig. 15(b). however, when parameter $b$ is less than $1.0 h$, the substructure with the FWFA connection will experience damage mode II, as shown in Fig. 15(c). These two damage modes are consistent with the expected damage modes in Fig. 5.

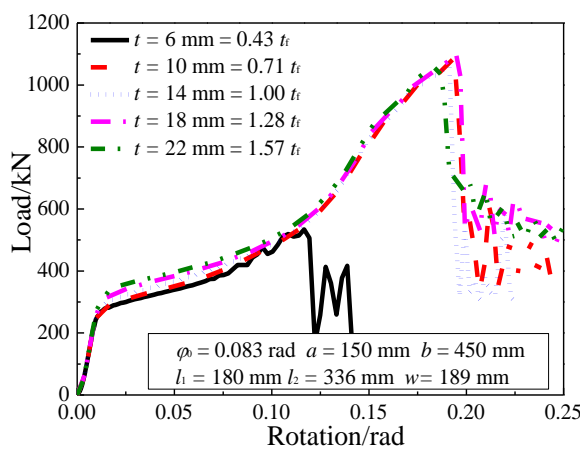

(a) Thickness

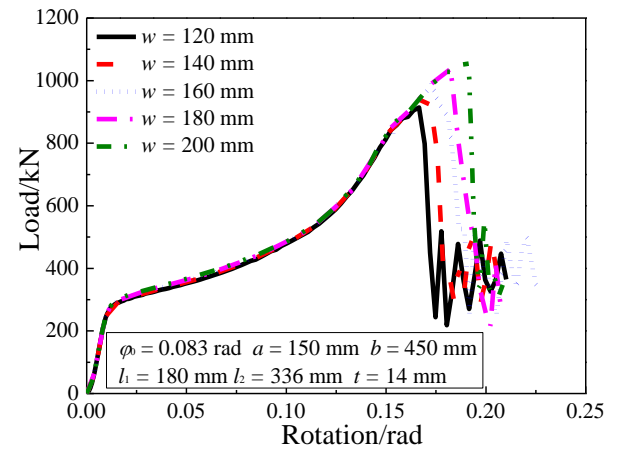

(b) Width

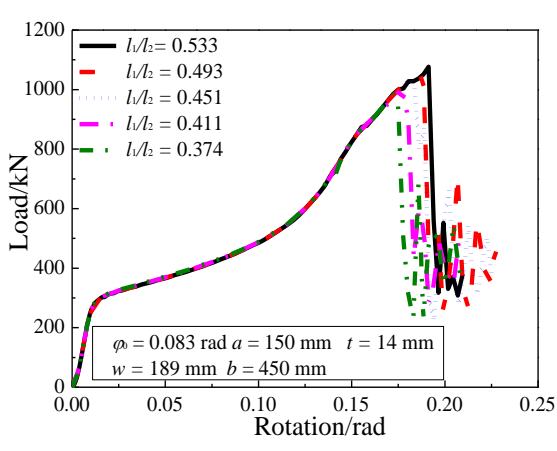

(c) Ratio of $/ l_{1} / l_{2}$

Fig. 14 Parameter analysis results of folded axillary plate 


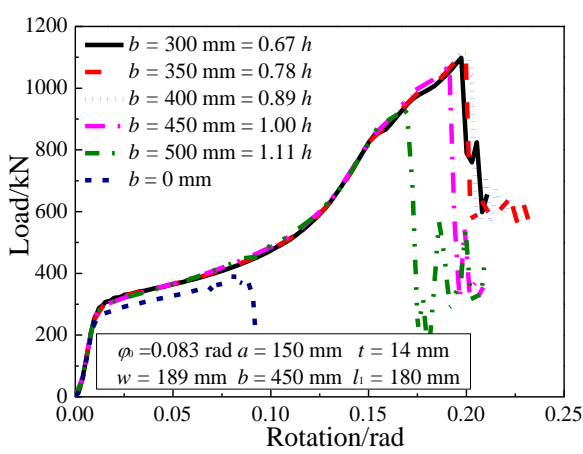

(a) Load vs. displacement

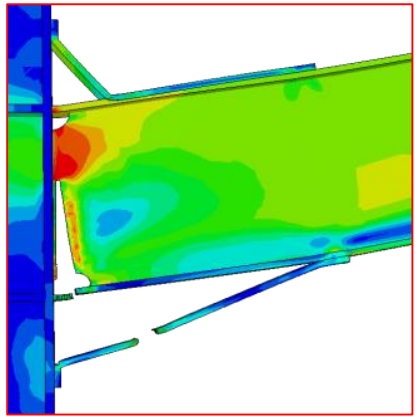

(b) Damage mode I

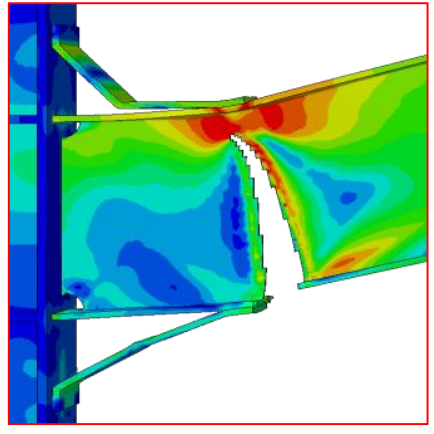

(c) Damage mode II

Fig. 15 Analysis results of parameter $b$

\subsection{Beam depth-to-span ratio}

In this section, the model specimen described in the previous section was used to discuss the influence of the beam depth-to-span ratio on the anti-collapse behavior of the structure with the FWFA connection. In the case of maintaining the height of the steel beam section $(h=450 \mathrm{~mm})$ and the other parameters $\left(\varphi_{0}\right.$ $=0.083 \mathrm{rad}, a=150 \mathrm{~mm}, b=450 \mathrm{~mm}, l_{1}=180 \mathrm{~mm}, l_{2}=150 \mathrm{~mm}, t=14 \mathrm{~mm}$, and $w=189 \mathrm{~mm}$ ) unchanged, only the length of the beam was changed. Six specimens were selected, and the lengths of the beams were 4500, 5400,6000, $7500,9000,10500$, and $11250 \mathrm{~mm}$. The depth-to-span ratios of these model specimens met the requirements of the standards for the design of steel structures in China [31].

Fig. 16 and Table 2 show the analysis results of the resistance and internal forces of the substructures with different beam depth-to-span ratios. In the initial stage, the load and internal forces of the substructures were different owing to the different flexural rigidities of the beams. With decreasing beam depth-tospan ratio, the resistance of the specimen decreased. Afterward, with the in- crease of the displacement of the middle column, all specimens entered the collapse resistance improved stage and obtained the maximum peak loads. At this time, with decreasing beam depth-to-span ratio, the maximum resistances and corresponding axial forces of the specimens first increased and then decreased. The bending moment at Section S1 decreased gradually; the axial force in the beams first increased and then remained at the yield value, except for the specimen with the beam depth-to-span ratio of 1/10, as shown in Fig. 16(c). For this specimen, the development of the beam axial force was insufficient and was interrupted before the yield value was reached, which led to the specimen to lose its bearing capacity too early. In addition, with decreasing beam depth-tospan ratio, the contribution of the flexural mechanism to the total resistance decreased gradually, whereas the contribution of the catenary mechanism to the total resistance increased gradually. This indicates that the continuous growth of the axial force in beam was key to realizing the collapse resistance improved stage of the substructure with the FWFA connections. Therefore, when the structure with the FWFA connections is designed to resist progressive collapse, it is suggested that the beam depth-to-span ratio of the steel frame structure is $1 / 12$ $1 / 20$.

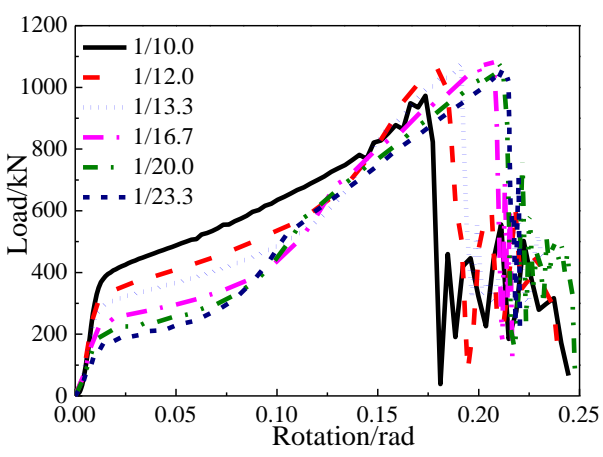

(a) Load vs. displacement

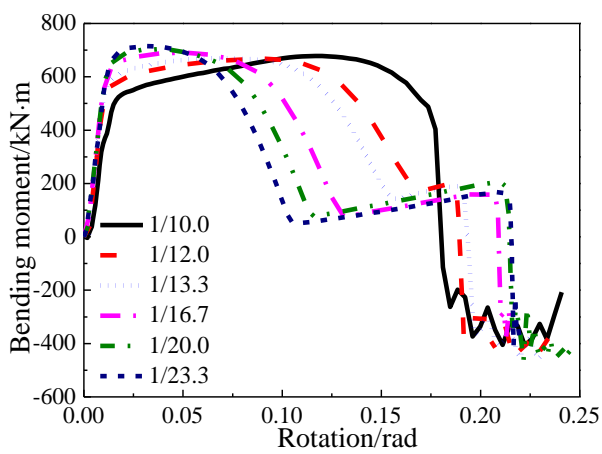

(b) Bending moments at Section S1

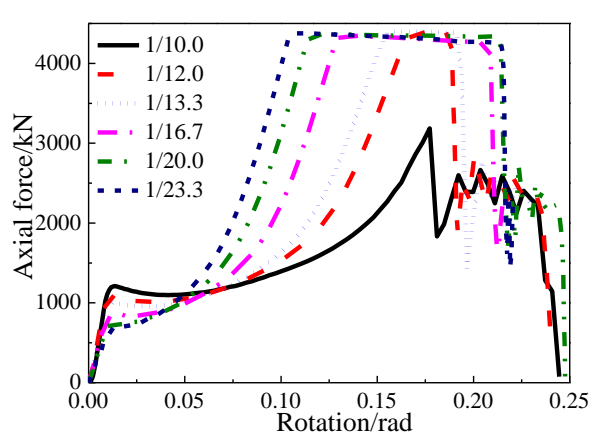

(c) Axial force in beam at Section S1

Fig. 16 Performance analysis results of subassemblies with FWFA connection

Table 2

Results of model specimens at the maximum peak point

\begin{tabular}{|c|c|c|c|c|c|c|c|}
\hline Specimens & $\begin{array}{l}\text { Length of } \\
\text { beam } / \mathrm{mm}\end{array}$ & Depth-to-span ratio & $\begin{array}{l}\text { Maximum re- } \\
\text { sistance/kN }\end{array}$ & Displacement/mm & Rotation/rad & $\begin{array}{l}\text { Bending mo- } \\
\text { ment } / \mathrm{kN} \cdot \mathrm{m}\end{array}$ & Axial force $/ \mathrm{kN}$ \\
\hline FWFA-L1 & 4500 & $1 / 10.0$ & 972.9 & 390.6 & 0.173 & 487.4 & 3011.3 \\
\hline FWFA-L2 & 5400 & $1 / 12.0$ & 1060.2 & 493.6 & 0.179 & 191.7 & 4390.4 \\
\hline FWFA-L3 & 6000 & $1 / 13.3$ & 1076.8 & 573.8 & 0.191 & 189.1 & 4384.1 \\
\hline FWFA-L4 & 7500 & $1 / 16.7$ & 1097.7 & 772.4 & 0.206 & 165.9 & 4366.7 \\
\hline FWFA-L5 & 9000 & $1 / 20.0$ & 1076.5 & 946.1 & 0.210 & 164.7 & 4350.2 \\
\hline FWFA-L6 & 10500 & $1 / 23.3$ & 1057.1 & 1112.2 & 0.212 & 161.1 & 4252.3 \\
\hline
\end{tabular}

\section{Conclusions}

In this study, the traditional full-welded connection is improved based on the folded axillary plates, which are arranged at the outer side of the beam-end flanges. On the basic of the theoretical analysis, the movement mechanisms of the tension- and compression-folded axillary plates are revealed. Through the validated numerical model, the anti-collapse behavior and key parameters of the improved connection (FWFA connection) are discussed, following which the design process of the folded axillary plate is given. The specific conclusions are as follows:

(1) Based on the theoretical analysis, the motion equation of the short and long legs of the folded axillary plate under the condition of progressive collapse is given, as shown in Eq. (8).

(2) When the design of the folded axillary plate is reasonable, the ultimate 
bearing capacity and deformation of the beam-column substructure will be simultaneously increased. Compared to the specimen with the full welded connection with the axillary plates, the specimen with the FWFA connection could obtain greater bearing capacity and deformation by the folded axillary plates. Its maximum deformation and corresponding bearing capacity could be increased by $49.9 \%$ and $53.5 \%$, respectively.

(3) The failure sequence of the substructure with folded axillary plates involved the folded axillary plate on the tension side first gradually straightening, followed by the two plastic regions forming at the beam flange. Subsequently, either the tension beam flange at the beam root and the folded axillary plate broke successively or the tension beam flange broke at the location where the plastic hinge moved outward.

(4) To improve the collapse resistance of the folded axillary plate, it is suggested through numerical parameter analysis that $a$ is $1 / 3 h ; b$ can be taken as $0.7-1.0 h ; t$ can be taken as $0.75-1.0 t_{\mathrm{f}}$; and the width of the folded axillary plate $w$ is calculated according to Eq. (16). The design process for the folded axillary plate is suggested, as shown in Fig. 7.

(5) When the structure with the FWFA connection is designed to resist progressive collapse, it is suggested that the beam depth-to-span ratio of the steel frame structure should be assumed to be $1 / 12-1 / 20$. When the ratio of the short to long leg of the folded axillary plate of the substructure with the FWFA connection is larger, the specimen will obtain a larger bearing capacity and deformation.

\section{Acknowledgements}

The research presented in this paper is supported by National Science Foundation for Young Scientists of China through Grant No. 51908449, Young talents program of Shaanxi Natural Science Basic Research Program through Grant No. 2020JQ-660, Scientific research plan projects of Shaanxi Education Department Program through Grant No.20JK0713, China Postdoctoral Science Foundation Funded Project through Grant No. 2018M643593, Talent Science and Technology of Xi'an University of Architecture and Technology through Grant No. RC1827, the National Natural Science Foundation of China through Grant No. 51678476, and the Key Research and Development Project of Shaanxi Province through Grant No. 2018ZDXM-SF-097. All opinions, findings, conclusions, and recommendations expressed in this paper are those of the writers and the authors have declared that no conflict of interest exists.

\section{References}

[1] The building regulations 2000, Part A, Schedule 1: A3, Disproportionate collapse, Office of the Deputy Prime Minister, London, 2004.

[2] EN 1991-1-7., Eurocode 1: Actions on structures. Part 1-7: General Actions-Accidental actions (CEN 2006), European Committee for Standardization, Brussels, 2006.

[3] GSA 2013. Alternate path analysis and design guidelines for progressive collapse resistance, United States General Services Administration, Washington, D.C., USA, 2013.

[4] UFC 4-023-03. Design of structures to resist progressive collapse, Department of Defense, Washington, D.C., USA, 2013.

[5] Japanese Society of Steel Urban Construction Council on Tall Buildings and Urban Habitat. Guidelines for Collapse Control Design-Construction of Steel Buildings with High Redundancy, Tokyo, Japan, 2004

[6] Yu J. and Tan K.H, "Special detailing techniques to improve structural resistance against progressive collapse", Journal of Structural Engineering, 140 (3): 04013077, 2014

[7] Wang W. and Qin X., "Retrofitted connection details of through diaphragm joint for structural robustness enhancement", Journal of Tongji University (Natural Science), 43(5): 685692,2015

[8] Meng B., Zhong W.H., Hao J.P., et al., "Improved steel frame performance against progressive collapse with infill panels", Journal of Constructional Steel Research, 158: 201-212, 2019

[9] Vasdravellis G., Baiguera M., Al-Sammaraie D., "Robustness assessment of a steel self-centering moment-resisting frame under column loss", Journal of Constructional Steel Research, 141: 36-49, 2018

[10] Wei J.P., Tian L.M., Hao J.P., et al., "Novel principle for improving performance of steel frame structures in column-loss scenario", Journal of Constructional Steel Research, 163: $105768,2019$.

[11] Qiang H.L., Yang J.X., Feng P., et al., "Kinked rebar configurations for improving the progressive collapse behaviours of RC frames under middle column removal scenarios", Engineering Structures, 211: 110425, 2020.

[12] Qiu L., Lin F., Wu K.C., "Improving progressive collapse resistance of RC beam-column subassemblages using external steel cables", Journal of Performance of Constructed Facilities, 34(1): 04019079, 2020.

[13] Gao S., Guo L.H., Zhang S.M., "Study on anti-collapse performance of semi-rigid composite joint strengthened by steel plate considering material damage", Journal of Building Structures, 40(3): 240-246, 2019.

[14] Lu X.Z., Zhang L., Lin K.Q., et al., "Improvement to composite frame systems for seismic and progressive collapse resistance", Engineering Structures, 170: 106119, 2020.

[15] Meng B., Zhong W.H., Hao J.P., et al., "Improving anti-collapse performance of steel frame with RBS connection", Journal of Constructional Steel Research, 158: 201-212, 2019

[16] Lew H.S., Main J.A., Robert S.D., et al., "Performance of steel moment connections under a column removal scenario. I: Experiments", Journal of Structural Engineering, 139(1): 98-107, 2013.

[17] Li L. Behavior of steel beam-to-column connections in structural progressive collapse, D.E., Tongji University, Shanghai, China, 2014.
[18] Meng B., Zhong W.H., Hao J.P., “Anti-collapse performances of steel beam-to-column assemblies with different span ratios", Journal of Constructional Steel Research, 140(1): 125 $138,2018$.

[19] Dinu F., Marginean I., Dubina D., "Experimental testing and numerical modelling of steel moment-frame connections under column loss", Engineering Structures, 151: 861-878, 2017.

[20] Stylianidis P.M., Nethercot D.A., "Modeling of connection behaviour for progressive collapse analysis", Journal of Constructional Steel Research, 113(6): 169-184, 2015.

[21] Yang B., Tan K.H., Xiong G., et al., "Experimental tests of different types of bolted steel beam-column joints under a central-column-removal scenario", Journal of Constructional Steel Research, 121: 341-351, 2016.

[22] Yang B., Tan K.H., "Experimental study about composite frames under an internal columnremoval scenario", Engineering Structures, 54: 112-30, 2013

[23] Meng B., Zhong W.H., Hao J.P., et al., "Calculation of the resistance of an unequal span steel substructure against progressive collapse based on the component method", Engineering Structures, 182: 13-28, 2019

[24] FEMA-267. Interim guidelines: evaluation, repair, modification and design of welded steel moment frames, Federal Emergency Management Agency, Washington, D.C.,1995.

[25] Sadek F., Main J.A., Lew H.S., et al., "An experimental and computational study of steel moment connections under a column removal scenario, NIST 1669", National Institute of Standards and Technology, 2010.

[26] ABAQUS Analysis User's Manual, 6.17, ABAQUS, Inc., Dassault Systemes. USA, 2017.

[27] Yang B. and Tan K.H., "Numerical analyses of steel beam-column joints subjected to catenary action", Journal of Constructional Steel Research, 70 (3): 1-11, 2012.

[28] Yang B., Tan K.H., Xiong G., "Behaviour of composite beam-column joints under a middlecolumn-removal scenario: Component-based modelling", Journal of Constructional Steel Research, 104:137-154, 2015.

[29] Jiang L., Wang X.L., Yang W.W. "Stress analysis of beam-column joint with different web corner cutting forms", Journal of Lanzhou University of Technology, 39(2): 106-109, 2013.

[30] Zhou T.H., Li W.C., Guan Y., et al., "Damage analysis of steel frames under cyclic load based on stress triaxiality", Engineering Mechanics, 31(7): 146-155, 2014.

[31] GB 50017-2017. Standard for design of steel structures, China Architecture \& Building Press, Beijing, China, 2017. 